Proceedings of the 32nd Annual Meeting of the Brazilian Embryo Technology Society (SBTE); Florianopólis, SC, Brazil, August 16th to 18th, 2018.

\title{
Expression of estrus as a relevant factor in fixed-time embryo transfer programs using estradiol/progesterone-based protocols in cattle
}

\author{
Gabriel A. Bón ${ }^{1,2,3,5}$, Andrés Cedeño $0^{1,3,4}$ \\ ${ }^{1}$ Instituto de Reproducción Animal Córdoba (IRAC), Zona Rural General Paz, Córdoba, Argentina. \\ ${ }_{2}^{2}$ Instituto de Ciencias Básicas, Medicina Veterinaria, Universidad Nacional de Villa María, Villa del Rosario, Córdoba, \\ Argentina. \\ ${ }^{3}$ Maestría en Reproducción Bovina, Facultad de Ciencias Agropecuarias, Universidad Nacional de Córdoba, Argentina. \\ ${ }^{4}$ Medicina Veterinaria, Escuela Superior Politécnica Agropecuaria de Manabí (ESPAM), Calceta, Manabí, Ecuador.
}

\begin{abstract}
The main objective of implementing embryo transfer in beef operations is to accelerate the rate of genetic progress in the herd. Among the main factors that affect the use of these technologies are related to nutrition, management and estrus synchronization. As a result of research conducted over the last 20 years, recipient utilization has increased by applying protocols that synchronize ovulation and allow for embryo transfer without the need for estrus detection, usually referred to as fixed-time embryo transfer (FTET). Although these protocols have performed adequately for several years, recent attention has been directed to the effect of estrus expression and estradiol concentrations during growth of the preovulatory follicle on embryo growth and pregnancy. The experiments reviewed herein demonstrate that estrus expression is associated positively with high pregnancy rates and reduced pregnancy losses in recipients receiving in vitroproduced and in vivo-derived frozen/thawed bovine embryos.
\end{abstract}

Keywords: embryo-fetal losses, estrus, recipients.

\section{Introduction}

The main objective of an embryo transfer program is to increase the genetic value of the offspring produced in a given herd. Nutrition, management and efficiency in the detection of estrus are among the factors that affect the use of these technologies (Mapletoft and Bó, 2016). The protocols that synchronize estrus and ovulation have allowed for embryo transfer at predetermined time, without the requirement for estrus detection. These protocols are usually referred to as fixed-time embryo transfer (FTET; Bó et al., 2002, 2012a). Although efforts to synchronize ovulation have resulted in cows ovulating in a shorter time interval as compared to untreated cycling animals, ovulation without expression of estrus often occurs. The objective of this manuscript is to briefly review protocols that are used to synchronize ovulation, and discuss how the expression of estrus may impact on pregnancy in embryo recipients.

\section{Conventional synchronization treatments for embryo recipients in South America}

Although prostaglandin F2 $\alpha$ (PGF2 $\alpha$ ) has been used most commonly for synchronization of estrus, the requirement for estrus detection and the variability in the interval from treatment to estrus and ovulation has adversely affected its performance in embryo transfer programs, especially in Bos indicus cattle (reviewed in Bó et al., 2002).

To avoid limitations associated with estrus detection, treatments that synchronize the time of ovulation, which were developed originally for fixedtime AI, have been utilized for FTET. These treatments are generally divided into those that are GnRH-based (Ambrose et al., 1999) and those that are estradiol-based (Bó et al., 2002). In either case, the recipient protocols include the insertion of a progesterone (P4) releasing device for 7 or 8 days (Hinshaw, 1999; Bó et al., 2002).

Estradiol and P4 (estradiol/P4)-based treatments are the most commonly used protocols to synchronize follicle wave emergence and ovulation of recipients in South America (Baruselli et al., 2010). The simplified protocol used most commonly nowadays consists of insertion of a P4-releasing device and the administration of $2 \mathrm{mg}$ estradiol benzoate (EB) on day 0 , and PGF2 $\alpha$ at the time of insertion and removal of the P4-device if it is impregnated with $>1 \mathrm{~g}$ of P4 and only at $\mathrm{P} 4$ device removal when it contains $<1 \mathrm{~g}$ of $\mathrm{P} 4$. The P4-device is usually removed on day 7 or 8 and 300 or $400 \mathrm{IU}$ of equine Chorionic Gonadotropin (eCG) is given at that time (Bó et al., 2002). Ovulation is induced by the administration of 0.5 or $1 \mathrm{mg}$ of estradiol cypionate (ECP) at the time of P4-device removal and all recipients with a CL receive an embryo 9 days later (i.e., 7 days after the expected time of estrus; Baruselli et al. 2010, 2011; Bó et al 2012a, b).

Overall, 75 to $85 \%$ of the recipients treated with this protocol receive an embryo (compared to 50\% or less with PGF2 $\alpha$ synchronization), P4 concentrations are high at the time of embryo transfer and pregnancy per embryo transfer (P/ET) usually exceeds $50 \%$, when both embryos and recipients are of high quality (reviewed in Bó et al., 2002; Baruselli et al., 2010, 2011). 


\section{Protocols that prolong the proestrus period}

Recent studies have suggested that reducing the length of exposure of the P4-releasing device insertion to 5 days and increasing the interval from P4-device removal to GnRH and fixed-timed AI to 3 days may improve pregnancy per $\mathrm{AI}(\mathrm{P} / \mathrm{AI})$ as compared to the traditional 7-day GnRH/P4 device protocol in beef cattle (Bridges et al., 2008). Furthermore, it was suggested that a reduction in the length of the growth phase of the ovulatory follicle prior to ovulation, as occurs in some animals treated with the conventional 7 day protocols, alters the steroidogenic capacity of the dominant follicle prior to ovulation and the resulting $\mathrm{CL}$, and decreases the ability of the uterus to support embryo development (reviewed in Bridges et al., 2013). Using a modified 5-day Co-Synch+CIDR protocol (no $\mathrm{GnRH}$ at P4 device insertion, PGF2 $\alpha$ at P4 removal on day 5 and GnRH on day 8) Sala et al. (2016) reported similar $\mathrm{P} / \mathrm{ET}$ rates with in vitro-produced embryos to those of recipients synchronized with two PGF2 $\alpha$ treatments 14 days apart and estrus detection. Based on these findings, we evaluated the effectiveness of an estradiol/P4 treatment protocol in which the exposure to P4 device was reduced to 6 days and proestrus was lengthened by the administration of GnRH $72 \mathrm{~h}$ after P4 device removal instead of ECP at device removal. The protocol for FTAI was named J-Synch (de la Mata and Bó, 2012). This treatment protocol has resulted in higher $\mathrm{P} / \mathrm{AI}$ rates in beef heifers compared to the conventional protocol in which the P4-device is removed on day 7 and ECP is given at that time (Bó et al., 2016).

A series of studies have been conducted recently to evaluate the performance of the J-Synch protocol in embryo transfer programs (Menchaca et al., 2015, 2016). The experiments were performed in Uruguay with 3,782 cycling Bos taurus beef recipients that received by FTET Holstein embryos produced invitro with sex-sorted semen. The first experiment compared pregnancy rates obtained with J-Synch protocol to the conventional estradiol/P4 protocol for FTET. All recipients received a P4-device (0.5 g progesterone, DIB 0.5, Zoetis, Uruguay) plus $2 \mathrm{mg}$ EB (Gonadiol, Zoetis) i.m on day 0. In the J-Synch group (n $=464)$, the DIB was removed on day 6 and $500 \mu \mathrm{g}$ cloprostenol (PGF2 $\alpha$, Ciclase DL, Zoetis) and $400 \mathrm{IU}$ eCG (Novormon, Zoetis) were given i.m and GnRH analogue (100 $\mu \mathrm{g}$ gonadorelin acetate, Gonasyn GDR, Zoetis) was given $72 \mathrm{~h}$ later. In the conventional treatment $(n=481)$, the DIB was removed on day 7 and PGF2 $\alpha$, eCG, and $0.5 \mathrm{mg}$ ECP (Cipiosyn, Zoetis) were administrated i.m. at the same time. The second experiment compared GnRH vs. EB to induce ovulation in the J-Synch protocol. The J-Synch protocol was performed as described previously with $\mathrm{GnRH}$ given at $72 \mathrm{~h}(\mathrm{n}=456)$ or $1 \mathrm{mg}$ EB given at $60 \mathrm{~h}$ after $\mathrm{P} 4$ device removal $(n=461)$. In experiment 3 , we evaluated the effect of the time of GnRH administration in the JSynch protocol $(\mathrm{GnRH}$ was given at $60 \mathrm{~h}(\mathrm{n}=452)$ or $72 \mathrm{~h}(\mathrm{n}=466)$ after device removal). For all the experiments, recipients received in vitro-produced embryos on day $16-17$ by FTET, and P/ET was determined by ultrasonography $40-50$ days later. Overall, the $\mathrm{P} / \mathrm{ET}$ rate was higher in the J-Synch $(49.4 \%, 229 / 464)$ than in the conventional synchronization protocol $(41.0 \%, 197 / 481 ; \mathrm{P}<0.05)$ group regardless of whether $\mathrm{GnRH}$ was administered at $72 \mathrm{~h}(58.8 \%, 230 / 391)$ or EB was administered at $60 \mathrm{~h}$ $(54.7 \%, 227 / 415)$; or whether GnRH was administered at $60 \mathrm{~h}(47.8 \%, 216 / 452)$ or $72 \mathrm{~h}(50.4 \%, 235 / 466)$. However, results suggest that prolonging the exposure to endogenous estradiol prior to ovulation, as it occurs with the J-Synch protocol, improved $\mathrm{P} / \mathrm{ET}$ with in vitroproduced embryos. It was also noteworthy that in a fourth study, in which cows $(\mathrm{n}=581)$ were treated with the J-Synch protocol (as described previously), but with some recipients being allowed to ovulate spontaneously $(\mathrm{n}=532), \mathrm{P} / \mathrm{ET}$ was greater for recipients that did not receive GnRH (57.5\%, 306/532 vs. 51.5\%, 299/58; $\mathrm{P}<$ $0.05)$. Results suggest that shortening the growth period of the ovulatory follicles with GnRH may adversely affect the chances of pregnancy in some cows. Thus, waiting for the natural expression of estrus may improve $\mathrm{P} / \mathrm{ET}$.

\section{Expression of estrus, preovulatory estradiol and the establishment of pregnancy}

Estrus is defined as the period in which a female is sexually receptive and it is due to increased circulating concentrations of estradiol at a time when P4 concentrations are low (Allrich, 1994). Furthermore, it has been suggested that the progression of events required for conceptus growth, elongation, survival and attachment are influenced by the coordination of events leading to a decrease in P4 concentrations and an increase in estradiol concentrations prior to the onset of estrus (Bridges et al., 2013). Additionally, preovulatory estradiol concentrations have been reported to have a positive impact on subsequent conceptus development, and cows that exhibit estrus have been reported to have a greater conceptus length on day 19 of gestation compared to those not exhibiting estrus (Davoodi et al., 2016).

It has been shown previously that the occurrence of estrus in FTAI programs is positively associated with $\mathrm{P} / \mathrm{AI}$ in Bos taurus (Richardson et al., 2016) and Bos taurus $x$ Bos indicus beef cattle (Bó et al., 2017), and with the diameter of the dominant follicle at FTAI, the diameter of the subsequent CL, the $\mathrm{P} 4$ concentrations in the luteal phase and P/AI in Bos indicus beef cattle (Sá Filho et al., 2011). Furthermore, diameter of the dominant follicle at the time of FTAI has been associated with pregnancy success in both Bos taurus (Lamb et al., 2001; Perry et al., 2004, 2005, 2007) and Bos indicus (Sa Filho et al., 2010). However, when postpartum beef cows were inseminated based on standing estrus, ovulatory follicle size had no influence on pregnancy success (Perry et al., 2005), indicating again that high estradiol concentrations produced by the dominant ovulatory follicle are essential for high P/AI (Perry et al., 2014). More specifically, follicle maturity may affect fertility through the preparation of the oocyte 
for embryo development, preparation of follicular cells for luteinization, and/or preparation of the uterine environment for the establishment of pregnancy. Therefore, the expression of estrus may affect P/ET in recipients synchronized with FTET protocols.

It has been previously shown that expression of estrus in Bos indicus $x$ Bos taurus recipients treated with the Ovsynch protocol resulted in greater diameter of the ovulatory follicle, subsequent $\mathrm{CL}$ area and $\mathrm{P} 4$ concentrations and greater $\mathrm{P} / \mathrm{ET}$ than in those that did not show estrus (Baruselli et al., 2003). The reasons for the higher $\mathrm{P} / \mathrm{ET}$ in the recipients showing estrus is that they were exposed to higher estradiol concentrations than those that were induced to ovulate with $\mathrm{GnRH}$ prior to showing estrus and the higher $\mathrm{P} 4$ concentrations at the time of FTET. In a recent study involving the reciprocal embryo transfer between donor cows and recipients induced to ovulate either a large or small dominant follicle with $\mathrm{GnRH}$ revealed interesting results (Atkins et al., 2013). In the study of Atkins et al. (2013), single embryos $(n=354)$ that were obtained from cows induced to ovulate a large or a small follicle with $\mathrm{GnRH}$ were transferred into recipients that were also induced to ovulate a small or a large follicle with GnRH. Pregnancy maintenance from 7 to 27 days of gestation was enhanced by increased serum estradiol concentrations at the time of the $\mathrm{GnRH}$ treatment and P4 concentration 7 days later in the recipient cows. However, this study also showed that follicle diameter was not all that important, as recipients with large follicles had the lowest pregnancy rates, indicating that estradiol produced by a new growing dominant follicle will benefit pregnancy more than an aged large dominant follicle that has already reduced estradiol production at the time of $\mathrm{GnRH}$-induced ovulation (Bridges et al., 2014). In another study, donor and recipient cows were retrospectively divided based on their plasma estradiol concentrations at induced ovulation (Jinks et al., 2013). In this study, circulating estradiol concentrations of the recipient cows, not the donor, was related to higher pregnancy rates, indicating that the primary benefit of increased preovulatory estradiol concentrations is mediated through alterations in the uterine environment of the recipient cows. Finally, two other studies in which estradiol treatments were administered to increase circulating estradiol concentrations prior to ovulation were conducted. Jinks et al. (2013) reported that the administration of $0.5 \mathrm{mg}$ ECP $24 \mathrm{~h}$ before AI increased P/AI in cows induced to ovulate a small dominant follicle $(<12.2 \mathrm{~mm})$ with GnRH. Madsen et al. (2015) treated ovariectomized cows with CIDR devices (1.38 g of P4, Zoetis, USA) to mimic the luteal phase and then treated with $2.5 \mathrm{mg}$ ECP $12 \mathrm{~h}$ after CIDR removal, $1.2 \mathrm{mg}$ EB $36 \mathrm{~h}$ after CIDR removal or no treatment $(\mathrm{CON})$ to mimic a preovulatory period. Ovulation was simulated with an injection of GnRH $48 \mathrm{~h}$ after CIDR removal and embryos were transferred on 7 days later. Pregnancy was maintained by administration of injectable P4 from days 3 to 6 and then CIDR devices until day 29. Cows that received estradiol treatments had greater embryonic survival and P/ET compared to control animals (4, 29, and $21 \%$ for $\mathrm{CON}, \mathrm{EB}$, and $\mathrm{ECP}$, respectively; Madsen et al., 2015).

\section{Expression of estrus and pregnancy rates in recipients treated with estradiol/P4-based FTET protocols}

After reviewing the previous studies, the effect(s) of estradiol concentrations and estrus expression on pregnancy rates in recipients in South America is unclear, since most are treated with estradiol/P4-based protocols. Furthermore, it would seem to be important to differentiate whether cows are induced to ovulate with $\mathrm{EB}$ or ECP; the resulting plasma estradiol-17 $\beta$ concentrations would be much higher for a shorter period of time in cows treated with EB as opposed to ECP (reviewed in Bó et al., 2013). In that regard previous results from our lab (Bó et al., 2012b) and others (Looney et al., 2010) have shown no significant effects of expression of estrus on $\mathrm{P} / \mathrm{ET}$ in recipients receiving $\mathrm{EB}$ as compared to the shorter acting estradiol-17 $\beta$ to induce ovulation.

A retrospective analysis of several experiments performed on 13 different commercial dairy farms in Brazil using an estradiol/P4-based protocol but with ECP rather than EB to induce ovulation revealed a positive association between estrus expression and fertility (Pereira et al., 2016). Pereira et al. (2016) observed that lactating dairy cows were either artificially inseminated $(\mathrm{n}=5430)$ or used as recipients $(n=2003)$. All cows were treated with a CIDR (Zoetis, Brazil) and $2 \mathrm{mg}$ EB on day 0, $25 \mathrm{mg}$ of dinoprost (Lutalyse, Zoetis) on day 7, and CIDR removal and 1 mg of ECP (Zoetis) on day 9. Cows were either FTAI on day 11 or FTET with fresh in vitro-produced embryos on day 18. Estrus was detected using tail-head devices (Estrotec, Rockway Inc., Spring Valley, WI) and pregnancy was determined on days 32 and 60 of gestation. Estrus expression positively influenced $(\mathrm{P}<$ 0.01 ) $\mathrm{P} / \mathrm{AI}$ on day 32 of gestation (estrus $38.9 \%$, $1785 / 4584$ vs. no estrus $25.5 \%, 222 / 846)$ and P/ET (estrus 46.2\%, 645/1397vs. no estrus 32.7\%, 193/606). Furthermore, pregnancy loss to day 60 was lower $(\mathrm{P}<$ 0.01 ) in cows that expressed estrus in FTAI (estrus $14.4 \%, 255 / 1785$ vs. no estrus $20.1 \%, 43 / 222$ ) and FTET (estrus $18.6 \%, 120 / 645$ vs. no estrus $22.7 \%$, 43/193). Similar results were also reported with crossbred Bos indicus $x$ Bos taurus beef heifers; the manifestation of estrus behavior up to 3 days after P4 device removal increased the probability of pregnancy in recipients receiving IVP embryos (Frade et al., 2014). Heifers expressing standing estrus had greater P/ET than heifers that did not express estrus $(62.4 \%, 106 / 170$ vs. $47.0 \%, 31 / 66 ; \mathrm{P} \leq 0.01)$. In addition, heifers that became pregnant had greater circulating P4 concentrations at FTET $(2.8 \pm 0.14 \mathrm{ng} / \mathrm{ml} ; \mathrm{n}=137)$ than those that did not become pregnant $(2.2 \pm 0.18 \mathrm{ng} / \mathrm{ml} ; \mathrm{n}$ $=99 ; \mathrm{P}=0.04$; Frade et al., 2014). Thus, the sequential exposure to greater concentrations of estradiol during the pre-ovulatory phase and the subsequent exposure to high P4 in the diestrus positively influenced pregnancy success after FTET. 
The potential practical drawback of these results was that doing embryo transfer in only the recipients that express estrus would reduce the proportion of recipients transferred/treated, which has been shown as one of the main benefits of using FTET programs in recipients in South America (Bó et al, 2002, 2012b; Baruselli et al., 2010, 2011).

Two other studies were performed in Argentina to confirm that the expression of estrus had a positive effect on P/FTET and maintenance of pregnancy in recipients treated with estradiol/P4-based protocols. A secondary objective was to evaluate if the administration of $\mathrm{GnRH}$ at the expected time of estrus to recipients not showing estrus would increase the proportion of recipients transferred and pregnant. In the first experiment, 729 non-lactating beef cows (Bonsmara $\mathrm{x}$ Bos indicus, Brangus and Braford) received a DIB $0.5 \mathrm{~g}$ device (Zoetis, Argentina) plus 2 $\mathrm{mg}$ of $\mathrm{EB}$ on day 0 and on day 8, DIBs were removed and $400 \mathrm{IU}$ of eCG (Novormon 5000, Zoetis) plus 0.5 $\mathrm{mg}$ of ECP (Cipiosyn, Zoetis) and $500 \mu \mathrm{g}$ of cloprostenol (Ciclase DL, Zoetis) were administered (Cedeño et al. 2017). All cows were tail-painted (CeloTest, Biotay S.A., Argentina) for estrus detection $(>30.0 \%$ paint loss $=$ estrus $)$. All recipients not showing estrus by $48 \mathrm{~h}$ (paint loss $\leq 30.0 \%$ ) were randomly divided to receive GnRH (100 $\mu \mathrm{g}$ of gonadorelin acetate; Gonasyn GDR, Zoetis) or no treatment. Estrus was again detected $56 \mathrm{~h}$ after $\mathrm{P} 4$ device removal and was recorded. On day 17, cows were examined by ultrasonography and those with a CL $\geq 18 \mathrm{~mm}$ (grade 1), $\geq 16$ and $<18 \mathrm{~mm}$ (grade 2 ) and $\geq 14$ and $<16 \mathrm{~mm}$ in diameter (grade 3) received in vivo-derived, frozen/thawed or in vitro-produced fresh embryos by non-surgical transfer. The overall proportion of recipients transferred was $88.1 \%(583 / 729)$ and the overall P/ET $46.0 \%(268 / 583)$. The proportion of recipients in estrus at 48 and $56 \mathrm{~h}$ after P4-device removal was $87.6 \%$ and $\mathrm{P} / \mathrm{ET}$ was higher $(\mathrm{P}<0.05)$ in recipients showing estrus $(48.3 \%, 250 / 518)$ than in those not showing estrus $(30.1 \%$; 22/73; Table 1$)$. When CL diameter at the time of FTET was considered, P/ET did not differ in recipients showing estrus that had a $\mathrm{CL} \geq 18 \mathrm{~mm}$ or between 16 and $18 \mathrm{~mm}$; however, $\mathrm{P} / \mathrm{ET}$ was lower in those not showing estrus, even in those with a $\mathrm{C} 18$ $\mathrm{mm}$ in diameter at the time of FTET $(\mathrm{P}<0.05$, Table 1$)$.

When the GnRH treatment was considered in recipients that did not expressed estrus by $48 \mathrm{~h}$ after DIB removal, $\mathrm{P} / \mathrm{ET}$ was significantly higher $(\mathrm{P}<0.05)$ in those treated with GnRH $(34 / 74,46.0 \%)$ than in those not treated with GnRH (12/46, 26.0\%). However, when the expression of estrus at $56 \mathrm{~h}$ after DIB removal was considered, P/ET were higher in those showing estrus, whether or not they received GnRH $(26 / 48,54.2 \%)$ than in those not showing estrus $(15 / 43,34.9 \%)$; and although the numbers were low, GnRH treatment did not appear to increase $\mathrm{P} / \mathrm{ET}$ in recipients that did not show estrus (GnRH: $38.0 \%, 8 / 21$ vs. no GnRH: $31,8 \%$, $7 / 22$ ).

A second study was conducted using nonlactating crossbred beef cows (205 Brangus and 198 Braford; Cedeño et al., 2018). On day 0 all animals received a DIB 0.5 device plus $2 \mathrm{mg}$ EB and then recipients were randomly allocated into two treatment groups. In recipients treated with the conventional estradiol/P4 synchronization protocol $\mathrm{P} 4$ devices were removed on day 8 and also received PGF $2 \alpha$, eCG and ECP at the same time. In recipients treated with the $\mathrm{J}$ Synch protocol P4 devices were removed on day 6 and received PGF2 $\alpha$ and eCG at the same time. All recipients were tail-painted and those not showing estrus by $48 \mathrm{~h}$ (conventional group) or $62 \mathrm{~h}$ (J-synch group) received $\mathrm{GnRH}$ at that time. Recipients were again run through the chute for tail-paint observation and recording $8 \mathrm{~h}$ later in both treatment groups. All cows with a CL received an in vitro-produced embryo by FTET 7 days after an observed estrus or GnRH treatment. The overall proportion of recipients transferred was $86.5 \%(352 / 407)$ and the overall P/ET was $37.8 \%(133 / 352)$. Although the proportion of recipients transferred was higher $(\mathrm{P}<0.05)$ in the conventional group $90.0 \%(180 / 201)$ than in the JSynch group $83.5 \% \quad(172 / 206)$, no significant differences were found in P/ET between the two synchronization protocols (Conventional: 36.6\%, $66 / 180$ vs. J-Synch $39.0 \%, 67 / 172$ ). However, the most important finding of this experiment was the great difference in P/ET and pregnancy losses between the recipients that showed estrus, regardless of treatment group. Recipients showing estrus had significantly higher $(\mathrm{P}<0.05) \mathrm{P} / \mathrm{ET}$ than those that did not show estrus (Table 2). Furthermore, recipients not showing estrus had a higher rate of embryonic/fetal losses between 30 and 60 days $(P=0.004)$ of gestation and consequently a lower $\mathrm{P} / \mathrm{ET}$ at 60 days and a lower calving rate $(\mathrm{P}<0.01$; Table 3$)$.

Results did not confirm previous studies in which $\mathrm{P} / \mathrm{ET}$ rates were $8.5 \%$ with the $\mathrm{J}$-Synch protocol (Menchaca et al., 2015). In fact, the small difference in favor of the J-Synch group was overridden by the higher proportion of recipients that were transferred in the conventional group. The differences in the proportion of recipients transferred/treated could be due to a higher ovulation rate in cows with small follicles that received ECP rather than GnRH (Jinks et al., 2013). However, the most interesting finding in the four studies reviewed in this section was the difference in P/ET between the recipients showing estrus and those not showing estrus, suggesting that the expression of estrus in FTET programs is linked to a uterine environment that favors embryo development (reviewed by Bridges et al., 2013 and Perry, 2017). As stated previously, even though recipients received $\mathrm{ECP}$ at the time of $\mathrm{P} 4$ device removal, those that manifested estrus probably had higher plasma estradiol concentrations resulting from ECP administration and from the developing ovulatory follicle than those not showing estrus. Therefore, recipients that showed estrus had sufficient estradiol exposure for the required changes in uterine environment for embryonic growth, survival and the establishment of pregnancy (Bridges et al., 2013).

This last study and that from Pereira et al. (2016) both showed a significantly higher rate of pregnancy loss in recipients not showing estrus. 
Surprisingly, pregnancy losses after 60 days were also higher in recipients not showing estrus. Embryo/fetal losses as high as $17.2 \%$ from day 32 to day 60 of pregnancy have been reported in dairy heifers (Garcia Guerra et al., 2016) and between 0 to $34,5 \%$ in beef cows (Tribulo et al., 2017) carrying IVF embryos. However, none of these reports related estrus expression to pregnancy losses from 60 days of gestation to term. During this period there is a continuous growth of the fetus and also dramatic changes in the placenta to meet the increasing nutritional demands of the growing fetus (reviewed by Wiltbank et al., 2017). Estimates of pregnancy loss during this period could range from 3$5 \%$ in recipients carrying in vivo-derived embryos to as much as $20 \%$ in recipients carrying in vitro-produced embryos (Bó and Cedeño, 2018, IRAC, Córdoba, Argentina, unpublished data). Factors associated with increased pregnancy loss in this period have not been studied in detail; however, the possibility of several infectious agents that can affect pregnancy during this period of time cannot be ruled out. Twinning was identified in one study as a major contributor to the pregnancy loss during this period (Lopez Gatius et al., 2004). However, this is not the case in the presently described study because all recipients received single embryos. Although other reasons may be related to the in vitro-produced embryo itself (Miles et al., 2005), this would not explain the differences observed between the recipients that did or did not show estrus. Obviously, more studies are required to confirm these findings.

Table 1. Effect of expression of estrus and CL diameter at the time of FTET on P/ET in recipient beef cows treated with an estradiol/P4-based synchronization protocol*.

\begin{tabular}{lcccc}
\hline & \multicolumn{4}{c}{ CL diameter $(\mathrm{mm})$} \\
\cline { 2 - 5 } & $\geq 18$ & $\geq 16 \&<18$ & $\geq 14 \&<16$ & Total \\
\hline \multirow{2}{*}{ Estrus } & $50.0^{\mathrm{o}} \%^{\mathrm{a}}$ & $44.2 \% \mathrm{o}^{\mathrm{ab}}$ & $13 . \%^{\mathrm{c}}$ & $48.3 \%^{\mathrm{a}}$ \\
\multirow{2}{*}{ No estrus } & $(203 / 406)$ & $(46 / 104)$ & $(1 / 8)$ & $(250 / 518)$ \\
& $37.0 \% \%^{\mathrm{b}}$ & $24.1 \%{ }^{\mathrm{b}}$ & $0 \%{ }^{\mathrm{d}}$ & $30.1 \%{ }^{\mathrm{b}}$ \\
\multirow{2}{*}{ Total } & $(15 / 41)$ & $(7 / 29)$ & $(0 / 3)$ & $22 / 73$ \\
& $48.8 \% \%^{\mathrm{a}}$ & $40.0 \%{ }^{\mathrm{a}}$ & $9.1 \%{ }^{\mathrm{b}}$ & \\
& $(218 / 447)$ & $(53 / 133)$ & $(1 / 11)$ &
\end{tabular}

${ }_{\text {abcd }}$ Denotes significant differences within rows and columns $(\mathrm{P}<0.05) .{ }^{*}$ All cows received $400 \mathrm{IU}$ eCG, $500 \mu \mathrm{g}$ cloprostenol and $0.5 \mathrm{mg}$ ECP at P4 device removal and observed for estrus (i.e. tail- paint loss) $48-56 \mathrm{~h}$ later.

Table 2. Pregnancy/ET as a function of the manifestation of estrus in recipients treated with two estradiol-based synchronization protocols.

\begin{tabular}{lccc}
\hline & \multicolumn{3}{c}{ Synchronization Treatment } \\
\cline { 2 - 4 } & Conventional* & J-Synch** & Total \\
\hline Estrus & $38,3 \%$ & $40,0 \%$ & $39,1 \%{ }^{\mathrm{a}}$ \\
& $(62 / 162)$ & $(62 / 155)$ & $(124 / 317)$ \\
No Estrus & $22,2 \%$ & $29,4 \%$ & $25,7 \% \mathrm{o}^{\mathrm{b}}$ \\
& $(4 / 18)$ & $(5 / 17)$ & $(9 / 35)$ \\
\hline
\end{tabular}

${ }^{\mathrm{ab}}$ Means within columns with different superscripts differed $(\mathrm{P}<0.05)$. $*$ Recipients in the Conventional protocol received $0.5 \mathrm{mg} \mathrm{ECP}$ at P4 device removal (Day 8) and were observed for estrus (i.e. tail-paint loss) 48 and $56 \mathrm{~h}$ later. **Recipients in the J-Synch protocol did not receive ECP at P4 device removal (Day 6) and were observed for estrus 62 and $70 \mathrm{~h}$ later. All recipients not showing estrus by $48 \mathrm{~h}$ (Conventional) or $62 \mathrm{~h}(\mathrm{~J}-\mathrm{Synch})$ received GnRH at that time.

Table 3. Effect of estrus expression on P/ET at 30 and 60 days of gestation, 30 to 60-d and 60-calving pregnancy loses and calving rate in recipients synchronized with two estradiol/P4-based treatments.

\begin{tabular}{lccccc}
\hline & $\begin{array}{c}\mathrm{P} / \mathrm{ET} \\
(30 \text { days })\end{array}$ & $\begin{array}{c}\mathrm{P} / \mathrm{ET} \\
(60 \text { days })\end{array}$ & $\begin{array}{c}\text { Pregnancy loss } \\
(30 \text { to } 60 \text { days })\end{array}$ & $\begin{array}{c}\text { Pregnancy loss } \\
(60 \text { days to calving })\end{array}$ & Calving rate \\
\hline Estrus & $39.1 \%^{\mathrm{a}}$ & $37,0^{\mathrm{a}}$ & $5,6 \%^{\mathrm{a}}$ & $20,5 \%^{\mathrm{c}}$ & $29,3 \%^{\mathrm{a}}$ \\
& $(124 / 317)$ & $(117 / 317)$ & $(7 / 124)$ & $(24 / 117)$ & $(93 / 317)$ \\
\multirow{2}{*}{ No Estrus } & $25,7 \%^{\mathrm{b}}$ & $8,6 \%^{\mathrm{b}}$ & $66,7 \% \%^{\mathrm{b}}$ & $66,7 \%^{\mathrm{d}}$ & $2,9 \% 0^{\mathrm{b}}$ \\
& $(9 / 35)$ & $(3 / 35)$ & $(6 / 9)$ & $(2 / 3)$ & $(1 / 35)$ \\
\hline \multirow{2}{*}{ Total } & $38,0 \%$ & $34,1 \%$ & $9,8 \%$ & $21,7 \%$ & $26,7 \%$ \\
& $(133 / 35)$ & $(120 / 352)$ & $(13 / 133)$ & $(26 / 120)$ & $(94 / 352)$ \\
\hline
\end{tabular}

${ }^{\mathrm{ab}}$ Denotes significant differences within columns $(\mathrm{P}<0.01) .{ }^{\mathrm{cd}}$ Denotes a tendency to differ $(\mathrm{P}<0.06)$. 


\section{Summary and final conclusions}

The protocols developed for FTET over the last 20 years have provided practitioners the greatest opportunity for transferring large number of embryos in recipient herds and has been pivotal for the development of the large scale IVF embryo-derived industry in South-America. Although overall pregnancy rates have been considered adequate for most practitioners, there are factors such as the expression of estrus that need to be considered for successful embryo transfer programs, especially in protocols in which ECP is used to induce ovulation or no estradiol is administered at the time of P4-device removal. The present manuscript has reviewed several studies showing a positive correlation between the manifestation of estrus, pregnancy rates and pregnancy maintenance in recipients. The use of tail-paint or estrus detection patches in recipients would help identify animals showing estrus by simply running them through the chute at the appropriate time, without the necessity of labor intensive estrus observations. These modifications can be easily implemented in recipient synchronization programs and should result in overall higher pregnancy rates.

\section{Acknowledgments}

Research was supported by Fondo Nacional de Ciencia y Tecnología (FONCYT PICT 2017-4550), Instituto de Investigación Universidad Nacional de Villa María (UNVM) and Instituto de Reproducción Animal de Córdoba (IRAC). We also thank our colleagues at IRAC and UNVM for technical assistance.

\section{References}

Allrich RD. 1994. Endocrine and neural control of estrus in dairy cows. $J$ Dairy Sci, 77:2738-2744.

Ambrose JD, Drost RL, Monson RL, Rutledge JJ, Leibfried-Rutledge ML, Thatcher MJ, Kassa T, Binelli M, Hansen PJ, Chenoweth PJ, Thatcher WW. 1999. Efficacy of timed embryo transfer with fresh and frozen in vitro-produced embryos to increase pregnancy rates in heat-stressed dairy cattle. J Dairy $S c i$ 82: 2369-2376.

Atkins, JA, Smith MF, MacNeil MD, Jinks EM, Abreu FM, Alexander LJ, Geary TW. 2013. Pregnancy establishment and maintenance in cattle. $J$ Anim Sci 91:722-733.

Baruselli PS, Marques MO, Carvalho NAT, Berber RCA, Valentim R, Carvalho Filho AF, Costa Neto WP. 2003. Dinâmica folicular e taxa de prenhez em novilhas receptoras de embrião (Bos taurus indicus $\mathrm{x}$ Bos taurus taurus) tratadas com o protocolo Ovsynch para inovulação em tempo fixo. Braz J Vet Res Anim Sci, 40:96-106.

Baruselli PS, Ferreira RM, Sá Filho MF, Nasser LFT, Rodrigues C, Bó GA. 2010. Bovine embryo transfer recipient synchronisation and management in tropical environments. Reprod Fertil Dev, 22:67-74.

Baruselli PS, Ferreira RM, Sales JNS, Gimenes LU, Sá Filho MF, Martins CM, Rodrigues CA, Bó GA. 2011. Timed embryo transfer programs for management of donor and recipient cattle. Theriogenology, 76:15831593.

Bó GA, Baruselli PS, Moreno D, Cutaia L, Caccia M, Tríbulo R, Tríbulo H, Mapletoft, RJ. 2002. The control of follicular wave development for selfappointed embryo transfer programs in cattle. Theriogenology, 57:53-72.

Bó GA, Baruselli PS, Mapletoft RJ. 2012a. Increasing pregnancies following synchronization of bovine recipients. Anim Reprod, 9:312-317.

Bó GA, Peres LC, Cutaia LE, Pincinato D, Baruselli PS, Mapletoft RJ. 2012b. Treatments for the synchronisation of bovine recipients for fixed-time embryo transfer and improvement of pregnancy rates. Reprod Fertil Dev, 24:272-277.

Bó GA, Baruselli PS, Mapletoft RJ. 2013. Synchronization techniques to increase the utilization of artificial insemination in beef and dairy cattle. Anim Reprod, 10:137-142.

Bó GA, de la Mata JJ, Baruselli PS, Menchaca A. 2016. Alternative programs for synchronizing and resynchronizing ovulation in beef cattle. Theriogenology, 86:388-396.

Bó GA, Cedeño A, Tribulo A, Andrada S, Tribulo R, Mapletoft RJ. 2017. Influence of estrus expression and treatment with GnRH on pregnancy rates in beef cattle synchronized with progesterone devices and estradiol and inseminated at a fixed time. Reprod Fertil Dev, 29:111. (Abstract).

Bridges GA, Helser LA, Grum DE, Mussard ML, Gasser CL, Day ML. 2008. Decreasing the interval between GnRH and PGF2 $\alpha$ from 7 to 5 days and lengthening proestrus increases timed-AI pregnancy rates in beef cows. Theriogenology, 69:843-851.

Bridges GA, Day ML, Geary TW, Cruppe LH. 2013. Deficiencies in the uterine environment and failure to support embryonic development. J Anim Sci, 91:30023013.

Bridges GA, Mussard ML, Hesler LA, Day ML. 2014. Comparison of follicular dynamics and hormone concentrations between the 7-day and 5-day CO-Synch + CIDR program in primiparous beef cows. Theriogenology, 81:632-638.

Cedeño A, Tribulo A, Andrada S, Barajas JL, Fonseca J, Ruiz A, Tribulo R, Tribulo H, Mapletoft RJ, Bó GA. 2017. Influence of estrus expression and treatment with GnRH on pregnancy rates in recipients synchronized with progesterone devices and estradiol and transferred at a fixed time. Reprod Fertil Dev, 29:159-160. (Abstract).

Cedeño A, Tríbulo P, Tríbulo A, Barajas JL, Ortega JA, Andrada JS, Lozano D, Monguillot I, Brandan A, Tribulo R, Tribulo H, Bó GA. 2018. Effect of synchronization treatment and estrus expression on conception rates and pregnancy loses in recipients receiving in vitro produced embryos. Reprod Fertil Dev, 30:181. (Abstract).

Davoodi S, Cooke RF, Fernandes AC, Cappellozza BI, Vasconcelos JL, Cerri RL. 2016. Expression of estrus modifies the gene expression profile in reproductive tissues on day 19 of gestation in beef cows. Theriogenology, 85:645-655.

de la Mata JJ, Bó GA. 2012. Estrus synchronization and ovulation using protocols with estradiol benzoate and GnRH and reduced periods of insertion of a 
progesterone releasing device in beef heifers. Taurus, 55:17-23.

Frade MC, Frade C, Cordeiro MB, Sá Filho M, Mesquita FS, Nogueira GP, Binelli M, Bertan Membrive CM. 2014. Manifestation of estrous behavior and subsequent progesterone concentration at timed-embryo transfer in cattle are positively associated with pregnancy success of recipients. Anim Reprod Sci, 151:85-90.

Garcia-Guerra A, Sala RV, Baez GM, Fosado M, Melo LF, Motta JCL, Leffers L, Walleser EA, Ochoa JC, Moreno JF, Wiltbank MC. 2016. Treatment with GnRH on Day 5 reduces pregnancy loss in heifers receiving in vitro-produced expanded blastocysts. Reprod Fertil Dev 28:185

Hinshaw RH. 1999. Formulating ET contracts. In: Proceedings Annual Meeting Society for Theriogenology, 1999, Nashville, TN, USA. Montgomery, AL: SFT. pp. 399-404.

Jinks EM, Smith MF, Atkins JA, Pohler KG, Perry GA, MacNeil MD, Roberts AJ, Waterman RC, Alexander LJ, Geary TW. 2013. Preovulatory estradiol and the establishment and maintenance of pregnancy in suckled beef cows. J Anim Sci, 91:1176-1185.

Lamb GC, Stevenson JS, Kesler DJ, Garverick HA, Brown DR, Salfen BE. 2001. Inclusion of an intravaginal progesterone insert plus $\mathrm{GnRH}$ and prostaglandin F2 $\alpha$ for ovulation control in postpartum suckled beef cows. J Anim Sci, 79:2253-2259.

Looney CR, Stutts KJ, Novicke AK, Chiles KC, Tijernia SE, Miranda AR, Romo S, Forrest DW. 2010. Advancements in estrus synchronization of Brahman-influenced embryo transfer recipient females. In: Proceedings AETA \& CETA/ACTE Joint Convention, 2010, Charlotte, NC, USA. Kemptville, ON, Canada: CETA/ACTE. pp. 17-22.

Lopez-Gatius F, Santolaria P, Yaniz JL, Garbayo JM, Hunter RHF. 2004. Timing of early foetal loss for single and twin pregnancies in dairy cattle. Reprod Domest Anim, 39:429-433.

Madsen CA, Perry GA, Mogck CL, Daly RF, MacNeil MD, Geary TW. 2015. Effects of preovulatory estradiol on embryo survival and pregnancy establishment in beef cows. Anim Reprod Sci, 158:96-103.

Mapletoft RJ, Bó GA. 2016. Bovine embryo transfer. In: International Veterinary Information Service (Ed.) IVIS Reviews in Veterinary Medicine. Ithaca: International Veterinary Information Service. (www.ivis.org; Document No. R0104.1106S).

Menchaca A, Dutra S, Carrau JM, Sapriza F, Salazar J, de la Mata JJ, Bó GA. 2015. Improvement of pregnancy rates by using the 6-day J-Synch protocol in recipient cows transferred with in vitro produced embryos. Anim Reprod, 12:653. (Abstract).

Menchaca A, Dutra S, Carrau JM, Sapriza F, Bó GA. 2016. Improvements of the new J-Synch protocol used for fixed-time embryo transfer (FTET) in recipients transferred with in vitro produced embryos. In: Proceedings of the 18th International Congress on Animal Reproduction (ICAR), 2016, Tours, France. Tours: ICAR. pp. 506. (Abstract).

Miles JR, Farin CE, Rodriguez KF, Alexander JE, Farin PW. 2005. Effects of embryo culture on angiogenesis and morphometry of bovine placentas during early gestation. Biol Reprod, 73:663-6671.

Pereira MHC, Wiltbank MC, Vasconcelos JLM. 2016. Expression of estrus improves fertility and decreases pregnancy losses in lactating dairy cows that receive artificial insemination or embryo transfer. $J$ Dairy Sci 99: 2237-2247.

Perry GA, Smith MF, Roberts AJ, Macneil MD, Geary TW. 2004. Effect of ovulatory follicle size on pregnancy rates and fetal mortality in beef heifers. $J$ Anim Sci, 82(suppl.1):102. (Abstract).

Perry GA, Smith MF, Lucy MC, Green JA, Parks TE, Macneil MD, Roberts AJ, Geary TW. 2005. Relationship between follicle size at insemination and pregnancy success. Proc Natl Acad Sci USA, 102:52685273.

Perry GA, Smith MF, Roberts AJ, Macneil MD, Geary TW. 2007. Relationship between size of ovulatory follicle and pregnancy success in beef heifers. J Anim Sci, 85:684-689.

Perry GA, Swanson L, Larimore L, Perry B, Djira GD. 2014. Relationship of follicle size and concentrations of estradiol among cows exhibiting or not exhibiting estrus during a fixed-time AI protocol. Domest Anim Endocrinol, 48:15-20.

Perry GA. 2017. Efecto de la madurez folicular sobre el establecimiento de la preñez. In: Proceedings XII Simposio Internacional de Reproduccion Animal, 2017, Cordoba, Argentina. Cordoba: IRAC. pp.171-190.

Richardson BN, Hill SL, Stevenson JS, Djira GD, Perry GA. 2016. Expression of estrus before fixed-time AI affects conception rates and factors that impact expression of estrus and the repeatability of expression of estrus in sequential breeding seasons. Anim Reprod Sci, 166:133-140.

Sá Filho MF, Crespilho AM, Santos JEP, Perry GA, Baruselli PS. 2010. Ovarian follicle diameter at timed insemination and estrous response influence likelihood of ovulation and pregnancy after estrous synchronization with progesterone or progestin-based protocols in suckled Bos indicus cows. Anim Reprod Sci, 120:23-30.

Sá Filho MF, Santos JEP, Ferreira RM, Sales JNS, Baruselli PS. 2011. Importance of estrus on pregnancy per insemination in suckled Bos indicus cows submitted to estradiol/progesterone based timed insemination protocols. Theriogenology, 76:455-463.

Sala RV, Carrenho-Sala LC, Fosado M, Tosta LCC, Tosta RD, Stoll M, Moreno JF, Monteiro BM, Baruselli PS, Garcia-Guera A, Wiltbank MC. 2016. Comparison of methods for synchronizing recipients of in vitro produced embryos. Reprod Fertil Dev, 28:185185.(Abstract).

Tribulo A, Cedeño AJ, Bernal B, Andrada S, Barajas JL, Ortega J, Oviedo J, Tribulo H, Tribulo R, Mapletoft RJ, Bó GA. 2017. Factors affecting pregnancy rates and embryo/fetal losses in recipients receiving in-vitro-produced embryos by fixed-time embryo transfer. Reprod Fertil Dev 29:160 (Abstract).

Wiltbank MC, Baez GM, Garcia-Guerra A, Toledo MZ, Monteiro PLJ, Melo LF, Ochoa JC, Sartori R. 2017. Momento y causas de la pérdida fisiológica de la preñez (no relacionada con enfermedad) en vacas lecheras lactantes y receptoras de embriones. In: Proceedings XII Simposio Internacional de Reproduccion Animal, 2017, Córdoba, Argentina. Cordoba: IRAC. pp. 73-102. 